\title{
Epidermal Trauma Reduces the Impact of Batrachochytrium dendrobatidis in Fowler's Toads (Anaxyrus fowleri)
}

\author{
Forrest Brem* and Matthew J. Parris
}

University of Memphis, Department of Biological Sciences, USA

\begin{abstract}
The amphibian epidermis presents many barriers that prevent pathogen infection. Much effort has been placed on examining determinants of infectivity and pathogenicity of Batrachochytrium dendrobatidis (Bd) in amphibians. However, no research has examined how trauma to the epidermis can affect susceptibility to and virulence of $B d$ infections in amphibians. Trauma is a common entry point for secondary infections that would otherwise be immunologically defensible to a host. The objective of our study was to determine if epidermal trauma would impact the outcome of $B d$ exposure. We predicted that epidermal trauma would make amphibians more susceptible to infection and result in more virulent infections. To test this prediction we compared susceptibility to infection, mortality, and survival time among three groups of Fowler's Toads, Anaxyrus fowleri (Hinckley); trauma and $B d, B d$ only, and no $B d$. Counter to our predictions we found that, with reference to negative controls, epidermal trauma and $B d$ together reduced susceptibility to infection, reduced overall mortality, and increased survival time compared to toads exposed to $B d$ only. Epidermal trauma is commonplace for wild amphibians, and is caused by predation attempts, combat, and unfavorable environmental conditions. We suggest that trauma to the epidermis preceding exposure to Batrachochytrium dendrobatidis elicits an innate immune response not initiated by the pathogen alone. Our data suggest that trauma could temporarily reduce susceptibility to, and virulence of, Batrachochytrium dendrobatidis infections of amphibians.
\end{abstract}

Keywords: Batrachochytrium dendrobatidis, chytridiomycosis, epidermis, trauma, susceptibility, amphibian disease.

\section{INTRODUCTION}

Diseases are one of the largest threats facing wildlife today, and amphibians have suffered the greatest disease induced declines and extinctions in history [1]. Chytridiomycosis is the disease caused by the fungal pathogen Batrachochytrium dendrobatidis $(B d)$ and has been posited as the primary cause of recent losses of amphibian abundance and species diversity observed on multiple continents [2]. Batrachochytrium dendrobatidis is now a panzootic pathogen of amphibians [2] and most species that have been experimentally exposed to this pathogen are susceptible (not resistant) to infection.

Susceptibility to infection is important because it represents one of the first stages in pathogen invasion [3]. A subsequent critical stage in this host pathogen system is virulence (severity of disease symptoms) of $B d$ infections. Unlike susceptibility, which is a binomial response, virulence of $B d$ infections (or pathogenicity of a parasite) falls along a continuum from avirulent infections (low pathogenicity) through highly virulent, lethal infections (high pathogenicity). Amphibians can vary in their susceptibility to $B d$ and, if infected, the virulence of infections can also vary at the individual, population, or species level $[4,5]$. The proportion of individuals that are susceptible to infection and the proportion that experience highly virulent infections

*Address correspondence to this author at the University of Memphis, Department of Biological Sciences, USA; Tel: 731-425-1970;

Fax:731-425-1916; E-mail: fbrem@memphis.edu within a population are especially important epizootiological parameters [3]. If some individuals are not susceptible to infection, the population cannot be driven to extinction by a parasite alone [3]. Likewise, Bd should not drive a population to extinction if some individuals were susceptible but do not experience virulent infections [3].

Host susceptibility to, and virulence of, $B d$ infections can vary among individuals due to endogenous factors such as genes for disease tolerance and resistance $[6,7]$. Exogenous factors including environmental conditions [8], the specific $B d$ isolate $[4,9]$, and the chemical environment of the amphibian epidermis $[10,11]$ have also been shown to influence susceptibility and virulence. In addition, the amphibian epidermis frequently endures mild to severe epidermal trauma from exogenous factors such as predation, combat with conspecifics, and parasitization [12]. In many disease systems, trauma is a common entry point for the establishment of secondary infections. Despite the importance of the amphibian epidermis to the pathogenesis of $B d$, no research has focused on how damage to the epidermis can affect the susceptibility of individuals to $B d$ infections and the virulence of resultant infections.

The amphibian epidermis is an evolutionarily unique organ and its function is more complex than the epidermis of most other vertebrates. The amphibian epidermis maintains homeostasis by regulating water, gas, and ion exchange and $B d$ kills amphibians by invading the epidermis and disrupting these functions [13]. Pathology of $B d$ infection is not fully understood but includes disruption of osmotic imbal- 
ance, mild epidermal lesions with focal hyperkeratinization, petechial hemorrhaging of the venter, and mild inflammation $[13,14]$. Batrachochytrium dendrobatidis invades the epidermis, thus, the epidermis represents the primary level of defense against $B d$ infection. A fully intact and functional epidermis presents many barriers to resisting $B d$ infection. We suspect that damage to the epidermis could impair the barriers that prevent parasites access to the amphibian host. The stratum corneum is the most superficial layer of the epidermis and is composed of dead cornified keratinocytes. Batrachochytrium dendrobatidis must penetrate the stratum corneum with a germ tubule to establish infection [15]. Granular glands of the epidermis also present barriers to $B d$ infection by the production of antimicrobial peptides [10]. In addition, mucous glands are present in the amphibian epidermis and are known to maintain a physical barrier to fungal infections in fish [16]. Regardless of the mechanism, it is clear that the amphibian epidermis plays a critical role in susceptibility to $B d$ infection.

Amphibian skin also plays a role in the virulence of $B d$ infection because immune responses resulting in resistance and tolerance are mediated by the epidermis. Trauma (physical damage), in a strict sense, is a disease because it disrupts normal anatomical structure and physiological function of affected tissues. Trauma causes rapid physiological changes in the amphibian epidermis through the initiation of immune responses and repair mechanisms, and changes in metabolic activity which are required for epidermal regeneration and repair. Epidermal repair following trauma in amphibians is similar to that of other vertebrates and involves four overlapping steps; hemostasis, inflammation, proliferation, and remodeling [17]. Briefly, hemostasis initiates repair with the release of endothelin from damaged cells causing vasoconstriction, platelet aggregation to seal off damaged blood vessels, and the release of fibrinogen and thrombin to complete the formation of the hemostatic plug. Soon after the initiation of hemostasis, inflammation commences and involves the recruitment of lymphocytes which remove foreign bodies and are important sources of and substrates for growth factors [18]. The proliferative and remodeling phases follow inflammation and are responsible for the formation of new blood vessels, epithelial cells, connective tissues, and scar formation at the site of the trauma. Finally, trauma initiates the release of hormones from the pituitary gland that increase metabolism and mobilize fuel stores, such as glycogen, to provide energy for epidermal repair [19]. Trauma may increase susceptibility by allowing $B d$ easier access to the epidermis or temporarily reducing immune function as a result of trauma as is seen in humans [20]. We also suspect that the virulence of infections in amphibians with epidermal trauma may be higher because host immunity may be dampened following trauma as is seen in humans [21].

Parasitic infections can be primary (able to infect an otherwise healthy individual) or secondary (can only infect following another disease). Recent infections, trauma, or unfavorable environmental conditions can alter an individual's susceptibility to secondary infection and allow the establishment of a pathogen that would otherwise be immunologically defensible to a host. For example, members of the fungal genus Saprolegnia (water molds) are ubiquitous in freshwater systems where they generally function as decom- posers. Water molds are only known to frequently cause primary infections in amphibian eggs [22, 23], however, they can establish secondary infections following recent infection, trauma, or mucosal depletion in some fish [24]. Once infections are established, water molds can cause mortality in many species of fish [24] and amphibians [25]. It is clear that $B d$ establishes primary infections in many amphibian species because many captive raised amphibians that have no other diseases are still highly susceptible to infection. However, it is unclear whether $B d$ can also cause secondary infections in less susceptible species or whether concomitant disease can increase susceptibility to Bd. Given the potentially high rate of concomitant trauma and pathogen exposure, enhanced pathogenesis of $B d$ as a secondary infectious agent may offer some insights into the severe negative impacts caused by $B d$ in numerous species.

Trauma disrupts the normal anatomical structure and physiological function of affected tissues. The objectives of our study were to assess whether $B d$ is more infectious and virulent as a secondary infection following epidermal trauma than as a primary infection without trauma. To test the efficacy of $B d$ as a secondary infectious agent we exposed one group of toads to $B d$ after administering mild epidermal trauma. We then compared susceptibility and virulence resulting from the above treatment to two other control groups of toads: a positive control group that received living $B d$ but no trauma, and the negative control group which received heat killed $B d$ and no trauma. We predicted that minor trauma of the epidermis would increase Fowler's toad's susceptibility to infection by allowing $B d$ easier invasion of the amphibian epidermis. We also tested whether such trauma would impact the virulence of $B d$ infection and mortality of toads due to $B d$ infection. We predicted that trauma would allow the establishment of more severe infections more rapidly, thus increasing the virulence of infection and resultant mortality. Finally, we tested whether survival times differed between the above treatment groups. We predicted that toads with secondary infections should have shorter survival times than positive and negative control toads.

\section{MATERIALS AND METHODOLOGY}

\section{Ethics Statement}

The experiments comply with the current laws of the USA. Collections of North American species were obtained by permits from the Tennessee Wildlife Resources Agency (permit \# 3054) and Tennessee Department of the Environment and Conservation (2007-001 and annual renewals). The use of vertebrates in our experiment was approved by the University of Memphis International Animal Care and Use Committee (permit \#'s 0650 and 0691).

\section{Anaxyrus Fowleri}

We collected partial egg masses of Anaxyrus fowleri from 3 populations in Shelby County, Tennessee: Edward J. Meeman Biological Field Station, TN $\left(35^{\circ} 23^{\prime} 22.66^{\prime \prime} \mathrm{N}\right.$ $\left.90^{\circ} 02^{\prime} 15.75^{\prime} \mathrm{W}\right)$; Meeman-Shelby State Park, (35²1'23.61” $\mathrm{N} 90^{\circ} 01^{\prime} 10.00^{\prime} \mathrm{W}$ ); and an artificial pond in urban Memphis TN $\left(35^{\circ} 09^{\prime} 18.18^{\prime \prime} \mathrm{N} 89^{\circ} 56^{\prime} 01.90 \mathrm{~W}\right)$. We collected a total of $\sim 1000$ eggs from at least three separate egg masses at each 
site. We collected all eggs between 14-23 April 2010. For each species, collection locations were separated by at least $4 \mathrm{~km}$ ensuring genetic independence of the source populations because Fowler's toads do not disperse long distances [26].

We hatched and reared $A$. fowleri in the lab in $\sim 40 \mathrm{~L}$ tanks using aged tap water. After hatching, we reared the larvae communally in groups of $\sim 50$ in shallow plastic containers (Sterilite ${ }^{\circledR} 1955$ 28qt under bed storage). We raised one side of the larval containers approximately $5 \mathrm{~cm}$ to make a slant. We chose this set-up for A. fowleri to mimic natural habitats and provide an oxygen gradient from the shallower to the deeper end. All larvae were fed daily on an ad lib 50:50 by weight diet of Sera Micron (sera GbmH ${ }^{\circledR}$ Gemany) and finely crushed Tetramin ${ }^{\circledR}$ tropical flakes (Tetra $\AA$ USA) until metamorphosis between mid-May and early-June 2010. We aerated the water with submersible aeration stones and an aquarium air pump. We changed $75 \%$ of the water in the containers weekly to prevent the accumulation of nitrogenous wastes. We removed all metamorphs upon emergence of the front legs to $1 \mathrm{~L}$ polyethelene cups with breathable lids, and $2.5 \mathrm{~cm}$ of moistened sphagnum moss.

Metamorphs were fed three times weekly on a size appropriate diet of fruit flies (Drosophila melanogaster and $D$. hydei) and European house crickets (Acheta domestica). We reared metamorphs until the majority of toadlets were over one gram before selecting individuals for the experiment. For the experimental groups, we selected toads that were of similar size $(\sim 1.25-1.50 \mathrm{~g})$ and age (between $90-120$ days post metamorphosis). From those remaining in the above size and age classes, we randomly selected 3 individuals from each population for each group to avoid possible parental and population effects. During the experiment, all amphibians were fed size appropriate Acheta domestica every third day at a rate equivalent to $0.1 \mathrm{~g}$ crickets per $1.0 \mathrm{~g}$ amphibian mass per day (e.g., $1 \mathrm{~g}$ frog fed $0.3 \mathrm{~g}$ crickets per feeding).

\section{Batrachochytrium Dendrobatidis Isolation and Exposure}

In a routine spring collecting trip, we found two female Lithobates sphenocephalus, one dead and one near death, heavily infected with $B d$ in the Meeman-Shelby State Park in early March 2010 during their breeding season. We were able to isolate $B d$ (FMB003) from one of the two L. sphenocephalus using the procedures outlined by Longcore et al. [27] with one exception: we used tryptone agar (10g tryptone, $10 \mathrm{~g}$ agar, $1 \mathrm{~L}$ deionized water) and tryptone broth $(10 \mathrm{~g}$ tryptone, $1 \mathrm{~L}$ deionized water) without antibiotics as media. After we isolated $B d$ FMB003, we transferred uncontaminated $B d$ colonies to tryptone broth. After achieving sufficient growth in the broth, we transferred $1 \mathrm{ml}$ of the broth to tryptone agar plates. We let those plates grow for one week before harvesting zoospores for the experimental inoculate. To make the inoculate, we flooded plates with $3 \mathrm{~mL}$ of deionized water, let them sit for one hour, collected the effluent, and filtered the effluent through a $20 \mu \mathrm{m}$ screen to remove most thalli. Finally, we used a hemocytometer to estimate zoospore density $(\sim 125,000$ zoospores $/ \mathrm{mL})$ before exposing the toads. To expose toads, we placed individuals in petri dishes with $3 \mathrm{ml}$ of the inoculate solution overnight for 12 hours and removed them to freshly prepared polyethelene cups similar to those used to rear them after metamorphisis described above.

\section{Experimental Design and Statistics}

We exposed groups of nine $A$. fowleri to three treatments (secondary infection $=$ SI; positive control $=\mathrm{PC}$; and negative control $=\mathrm{NC}$ ). Frogs of the secondary infection group (SI) were the treatment group. Immediately before we exposed them to $B d$ FMB003, we subjected SI frogs to mild epidermal trauma to mimic a mild trauma that could be experienced in nature. We considered successful $B d$ infections in this group to be secondary infections following trauma to the epidermis. Using an IACUC approved method equivalent to scraping the epidermis of live animals to assay for $B d$ by light microscopy, we imposed epidermal trauma by scraping the venter of the frog with tip of a scalpel blade 20 times and the inferior side of each foot five times. After this process, we could observe reddening of the venter and digits but never any lacerations. Frogs of the positive control group (PC) were not subjected to any trauma but were only exposed to $B d$ FMB003. We considered successful Bd infections in this group to represent primary infections. Frogs of the negative control group (NC) were subjected to the trauma procedure described above and heat killed Bd FMB003 to control for the effects of the trauma and exposure procedures. We heat killed $B d$ by leaving the inoculate in a warming oven at $75^{\circ} \mathrm{C}$ for one hour.

After exposure, we censused toads daily for changes in behavior, morbidity, and mortality. We recorded dates of all mortality events for survival analysis. To test for differences in susceptibility and mortality among treatments we used a Fisher's exact test. For the Fisher's exact tests we used $\mathrm{SAS}^{\circledR}$ 9.3 (SAS Institute Inc.). To test for a difference in survival times (time from exposure to mortality) we used a KaplanMaier log-rank survival analysis. For the survival time analysis we used Sigma Plot ${ }^{\mathrm{TM}} 12$ (Systat Software Inc.). For the Fisher's exact test, we considered toads susceptible to $B d$ infection as those where we could confirm definite $B d$ infection by presence of thalli using light microscopy. We assayed for the presence or absence of $B d$ using light microscopy of skin slough at the time of mortality or at 4 weeks, whichever came first, and again at the conclusion of the experiment. We chose four weeks because it is a common time to morbidity in other studies [28]. We also repeated the assay at signs of morbidity after four weeks and again at the conclusion of the experiment, at day 70 , on all survivors. We concluded at 70 days because all remaining toads showed no clinical signs of $B d$ as the others did preceding mortality. Also, the skin scrapes of the remaining toads revealed no $B d$ thalli or easily removable skin slough, which a common symptom of $B d$ infection. In addition, the remaining animals survived for over two years in an educational display and were $B d$ free when they eventually died of unknown causes.

\section{RESULTS}

\section{Susceptibility}

We found overall significant differences in susceptibility among treatment groups (Fisher's exact test, $p=0.0026$ ) 
caused by the significantly greater susceptibility of PC relative to NC toads (Fisher's exact test, $p=0.0023$, Fig. 1). Susceptibility of SI toads, however, was similar to both PC toads (Fisher's exact test, $p=0.1534$ ) and NC toads (Fisher's exact test, $p=0.21)$. Thus, with respect to the negative controls (NC), toads with primary $B d$ exposures (PC) were more susceptible to infection than toads with secondary exposures (SI).

\section{Mortality}

All toads that were diagnosed with $B d$ infection eventually died. In addition, one additional toad in each group died before day 70 but was not infected with $B d$. We found over- all significant differences in mortality among treatment groups, (Fisher's exact test, $p=0.0048$ ) caused by the significantly greater mortality of PC relative to NC toads, (Fisher's exact test, $p=0.0034$, Fig. 2). Mortality of SI toads, however, was similar to both PC toads (Fisher's exact test, $p=0.13$ ) and NC toads (Fisher's exact test, $p=0.29$ ). Thus, with respect to the negative controls (NC), toads exposed to $B d$ but no trauma (PC) suffered higher mortality than toads with secondary infections following trauma (SI).

\section{Survival Time}

Kaplan-Meier survival analysis (Fig. 3) revealed a significant difference in survival time among groups (log-rank

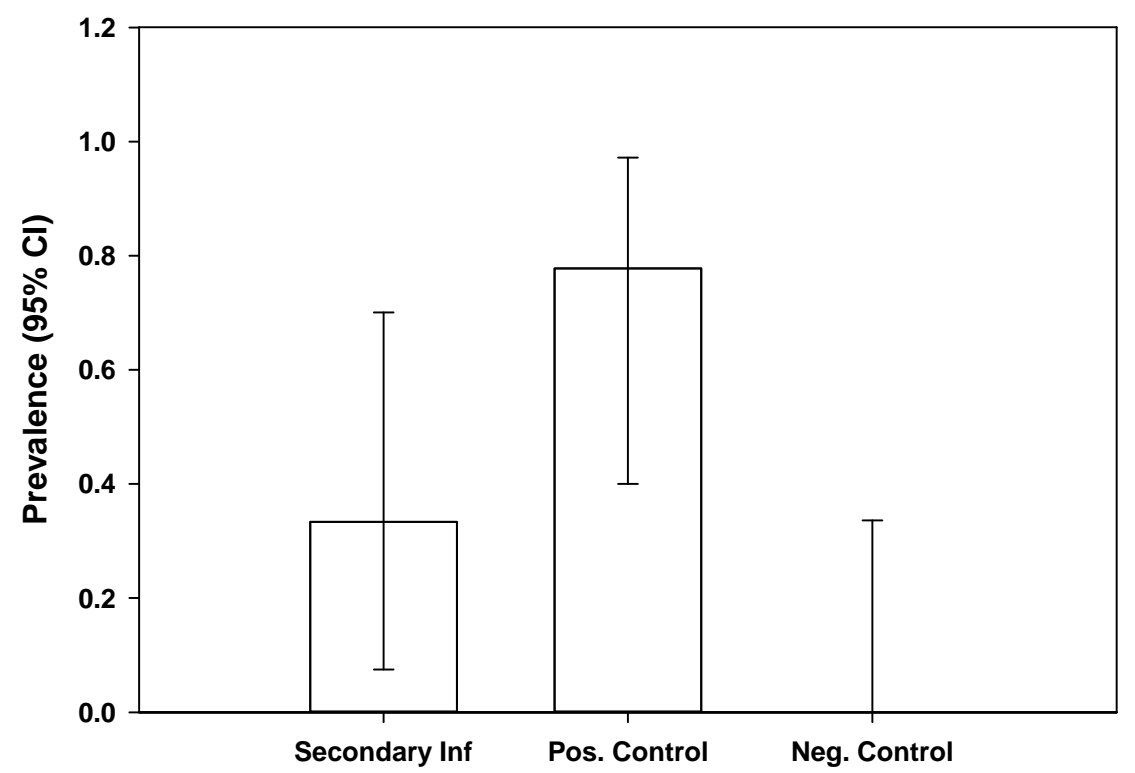

Fig. (1). With reference to negative controls (neg. control), Anaxyrus fowleri exposed to Batrachochytrium dendrobatidis alone (pos. control.) were less susceptible to infection than those exposed to $B d$ following epidermal trauma. Different letters indicate significance at $\mathrm{p}<$ 0.05 .

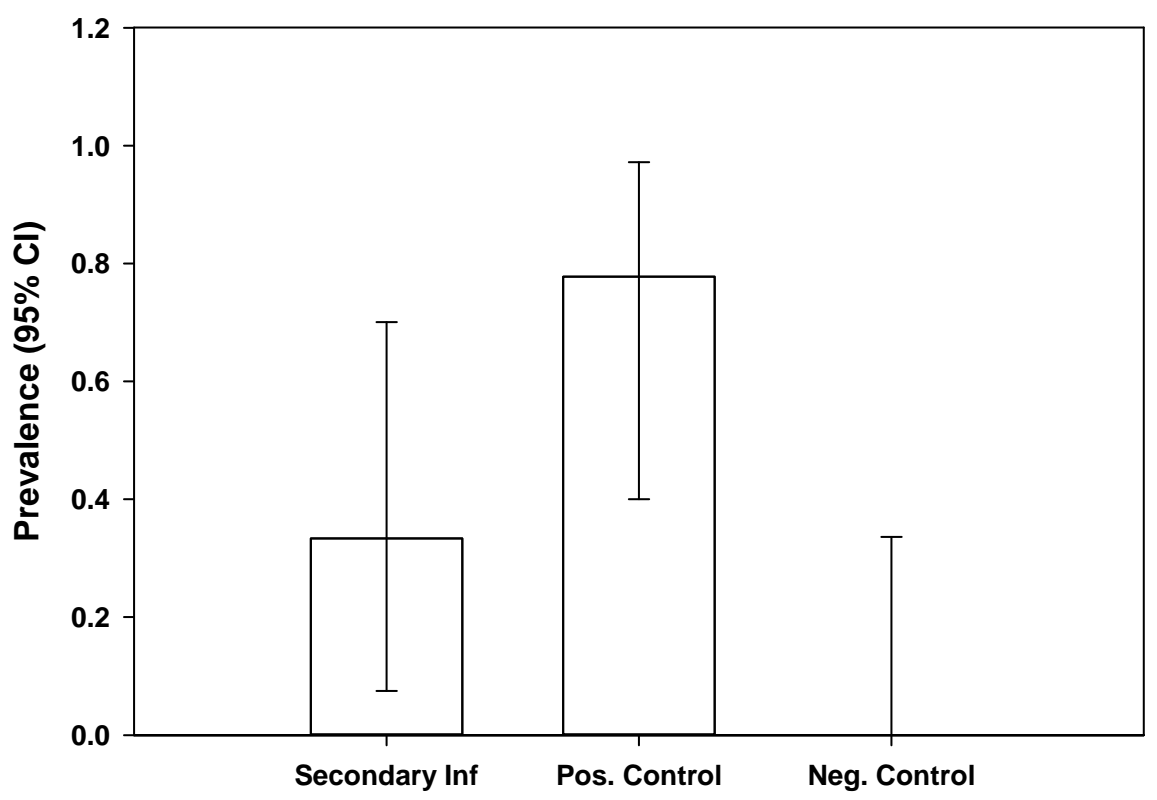

Fig. (2). With reference to negative controls (neg. control), Anaxyrus fowleri exposed to Batrachochytrium dendrobatidis alone (pos. control.) suffered higher mortality than those exposed to $B d$ following epidermal trauma. Different letters indicate significance at $\mathrm{p}<0.05$. 
test, $\mathrm{z}=11.34 \mathrm{df}=2 \mathrm{p}=0.003$ ). Positive Control toads had significantly shorter survival times than NC toads (Holm-Sidak $\mathrm{p}=0.00259$ ), but the SI toads had similar survival times to both NC toads (Holm-Sidak $\mathrm{p}=0.082)$ and PC toads (HolmSidak $\mathrm{p}=0.125$ ).

\section{DISCUSSION AND CONCLUSIONS}

We have clearly demonstrated that, under our experimental conditions, $B d$ was most successful as a primary infection of A. fowleri. We predicted that mild epidermal trauma, similar to that which can occur in nature, would increase the susceptibility of $A$. fowleri to $B d$. However, mild epidermal trauma did not allow $B d$ to more easily establish infections. Rather, trauma hindered the establishment of $B d$ infection. Specifically, our data show that, with reference to negative controls, mild epidermal trauma reduced susceptibility of toads to $B d$ infection (Fig. 1). Although our light microscopy assay could have underestimated susceptibility in our study, we can confidently state that our data contains no false positives. Additionally, our microscopy assay had no effect on our measures of mortality and survival time. Furthermore, our susceptibility data closely mirrored our mortality and survival time data where toads we diagnosed with $B d$ infections eventually died.

We also predicted that secondary infections following trauma would result in higher overall mortality and shorter survival times. Our results also indicate that, with reference to our negative controls, infections were most virulent in toads that received $B d$ but no trauma. Mortality resulting from $B d$ exposures following trauma was similar to that of negative controls (Fig. 2) whereas mortality of toads with $B d$ alone was significantly higher than negative controls. Survival times of toads in the trauma group were also similar to those of negative controls (Fig. 3) whereas toads with $B d$ alone were again different. These results were contrary to our predictions and suggest that some effect of the trauma procedure resulted in toads being less susceptible to infection or quickly clearing $B d$ infections before progressing to chytridiomycosis.

The amphibian epidermis presents many barriers to infection, but $B d$ alone does not illicit the full suite of epidermal defenses in all amphibians [29, 30]. We speculate that our trauma procedure resulted in the stimulation of an immunological response that $B d$ would not normally illicit in Fowler's toads and, therefore, $B d$ would not have to overcome to establish infection. One likely mechanism is the inflammatory response, however, alternative explanations do exist. Inflammation is a component of innate immunity and is a nonspecific immunological defense meant to eliminate the source of an injury and initiate healing. The inflammatory response initiates a suite of chemical and cellular defenses that may have been effective at preventing the establishment of $B d$ infection in our study [31]. In addition, innate and adaptive immunity are cross-linked; thus, an inflammatory response could recruit components of the adaptive immune system to prevent or eliminate $B d$ infection [32]. Evolutionary immunology of $B d$ and amphibians is a developing area of research. Our data suggest that inflammation could provide protection from $B d$ in nature. Given this, it would be valuable to examine whether amphibian species with robust inflammatory responses are those more likely to persist with $B d$. Finally, our results only concern secondary infection following epidermal trauma. It is likely that secondary $B d$ infections following other primary diseases (i.e. parasitic infections, toxicosis, stress) would not result in decreased susceptibility and virulence of $B d$ infections. Rather, we would expect that primary diseases other than trauma would increase susceptibility to and virulence of $B d$ infections.

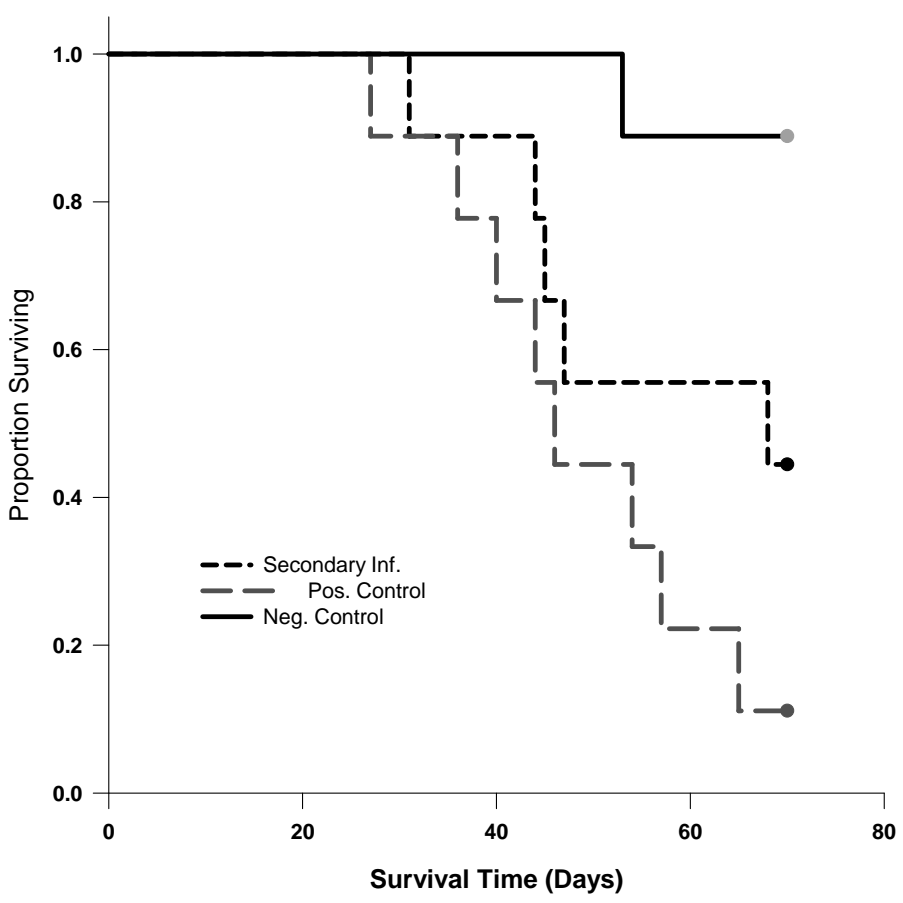

Fig. (3). With reference to negative controls (neg. control), Anaxyrus fowleri exposed to Batrachochytrium dendrobatidis alone (pos. control.) had shorter survival times than those exposed to $B d$ following epidermal trauma. Different letters indicate significance at $\mathrm{p}<0.05$. 
Alternative explanations to the inflammatory response also exist. Amphibians slough their stratum corneum regularly as a part of growth and epidermal regeneration [33]. Hyperkeratosis and increased sloughing of the epidermis are common symptoms documented in amphibians infected with $B d$ [34-36]. If $B d$ is unable to penetrate deeper epidermal layers below the stratum corneum before the epidermis is sloughed, or reinfect the amphibian during the sloughing process, an amphibian may be able clear a $B d$ infection. In addition, sloughing may reduce the virulence of infection by the removal of impaired epidermal layers. Although we did not directly measure the sloughing rate, we did not observe an obvious increase in sloughing during our study.

The chemical environment of the amphibian epidermis also impacts susceptibility to and virulence of infection [10, 11,29]. Antimicrobial peptides are produced endogenously by granular glands $[10,29]$ and exogenously through natural microbial fauna of the epidermis [11]. Antimicrobial peptides have been shown to reduce the susceptibility of an individual to $B d$ infection and may also influence virulence of infection. Epidermal trauma is known to elevate production and release of antimicrobial peptides in amphibians [37, 38], which could prevent infection if the peptides are efficacious killers of $B d$. We did not test antimicrobial peptide levels in our study, thus, we cannot dissect the effect of antimicrobial peptides from the effects of inflammation. Thus, future research warrants determining the relative importance of elevated peptide levels versus components of the inflammatory response in reducing the negative effects of $B d$ following trauma.

Finally, the mucosal layer on the epidermis of many amphibians may represent another barrier that $B d$ must overcome before establishing an infection. Ictalurus catfish farmed in the southern United States are more susceptible to infection by Saprolegnia in the winter months because the mucosal layer is thinner, and immunological function is reduced, in cold conditions [39]. In the Saprolegnia-catfish system, susceptibility is higher in cold conditions because the thinner mucosal layer allows easier penetration of this pathogen's germ tube into the epidermis [39]. Like Saprolegnia, $B d$ initiates infection by penetrating the host's epidermis with a germ tubule [15]. Thus, the thickness of the amphibian epidermal mucus layer may represent an additional barrier to infection that has yet to be explored. If epidermal trauma resulted in rapid elevated mucous production, perhaps it could have prevented $B d$ infection of the SI group in our study. We suggest this alternative is the least likely because, although toads do have mucus producing glands in their skin, toads are generally dry skinned and an appreciable mucus layer is generally not present on the surface of their skin.

We have shown that epidermal trauma preceding $B d$ exposure any susceptibility to infection, reduced mortality from infection, and increased survival times in A. fowleri compared to toads exposed to $B d$ exposure without trauma. Our experimental groups had relatively low sample sizes. Thus, to detect a significant difference with such a small sample size, the effect size of the treatment was likely very high. Although our data are compelling, we recognize that low sample size and taxonomic coverage are limitations of our study. Also, we did not use qPCR, and acknowledge that quantitative measures of zoospore load would have provided a more precise, continuous variable with which to evaluate virulence of $B d$ infection. In addition, qPCR could have identified light infections that our microscopy assay may have missed. Regardless, our assay did not affect our measures of mortality or survival time, both of which mirrored our susceptibility data. Despite these limitations, we are confident that our results demonstrate a compelling interaction between host epidermal trauma and infectivity and virulence of a deadly pathogen of amphibians. Finally, we suggest that our results clearly demonstrate how exogenous factors can influence $B d$ pathogenicity and urges further work to detail the mechanism by which epidermal trauma reduces susceptibility and virulence of $B d$ infection in amphibians.

\section{CONFLICT OF INTEREST}

The authors confirm that this article content has no conflicts of interest.

\section{ACKNOWLEDGEMENTS}

We would like to thank Shane Hanlon for insightful comments to the manuscript. We would also like to thank The University of Memphis Department of Biological Sciences for permitting collections at the University of Memphis Edward J Meeman Biological Field Station. This work was funded by a conservation grant from the North England Zoological Society and the Chester Zoo, United Kingdom. We have no conflicts of interest concerning the research detailed in this manuscript.

\section{REFERENCES}

[1] Wake DB, Vredenberg VT. Are we in the midst of the sixth mass extinction? A view from the world of amphibians. Proc Natl Acad Sci U S A 2008; 105: 11466-73.

[2] Skerratt LF, Berger L, Speare R, Cashins S, McDonald K R, Phillott AD, Hines HB, Kenyon N. Spread of chytridiomycosis has caused the rapid global decline and extinction of frogs. Ecohealth 2007; 4: 125-34.

[3] Anderson RM, May RM. Population biology of infectious diseases: Part 1. Nature 1979; 280: 361-367.

[4] Ghal MK, Longcore JE, Houlahan JE. Varying responses of Northeastern North American amphibians to the Chytrid pathogen Batrachochytriun dendrobatidis. Conserv Biol 2012; 26: 135-41.

[5] Searle CL, Gervasi SS, Hua J, Hammond JI, Relyea RA. Differential Host Susceptibility to Batrachochytrium dendrobatidis, an Emerging Amphibian Pathogen. Conserv Bio 2011; 25: 965-74.

[6] Farrer RA, Weinert LA, Bielby J, Garner TWJ, Balloux F, Clare F, Bosch J, Cunningham AA, Weldon C, du Preez LH, Anderson L, Pond SLK, Shahar-Golan R, Henk DA, Fisher MC. Multiple emergences of genetically diverse amphibian-infecting chytrids include a globalized hypervirulent recombinant lineage. Proc Natl Acad Sci U S A 2011; 108: 18732-6.

[7] Savage AC, Zamudio KR. MHC genotypes associate with resistence to a frog-killing fungus. Proc Natl Acad Sci U S A 2011; 108 : 16705-16710.

[8] Berger L, Speare R, Hines HB, et al. Effect of season and temperature on mortality in amphibians due to chytridiomycosis. Aust Vet J 2008; 82: 434-39.

[9] Berger L, Marantelli G, Skerratt LF, Speare R. Virulence of the amphibian chytrid fungus Batrachochytrium dendrobatidis varies with the strain. Dis Aquat Organ 2005; 68: 47-50.

[10] Woodhams DC, Ardipradja K, Alford RA, Marantelli G, Reinert LK, Rollins-Smith LA. Resistence to chytridiomycosis varies among amphibian species and is associated with skin peptide defenses. Anim Conserv 2007; 10: 409-17. 
[11] Harris RN, James TY, Lauer A, Simon MA, Patel A. Amphibian pathogen Batrachochytrium dendrobatidis is inhibited by the cutaneous bacteria of amphibian species. Ecohealth 2006; 3: 53-6.

[12] Oullete, M. Amphibian deformities: Current state of knowledge. In Sparling DW, Linder G, Bishop CA, Eds. Ecotoxicology of Amphibians and Reptiles. Pensacola, FL. SETAC. 2000; pp. 617-61.

[13] Voyles J, Young S, Berger L, Campbell C, Voyles WF, Dinudom A, Cook D, Webb R, Alford RA, Skerratt LF, Speare R. Pathogenesis of chytridiomycosis, a cause of catastrophic amphibian declines. Science 2009; 326: 582-585.

[14] Berger L, Speare R, Skerratt LF. Distribution of Batrachochytrium dendrobatidis and Pathology in the skin of green tree frogs Litoria caerulea with severe chytridiomycosis. Dis Aquat Organ 2005; 68: $65-70$.

[15] Longcore JE, Pessier AP, Nichols DK. Batrachochytrium dendrobatidis gen. et sp. nov., a Chytrid pathogenic to amphibians. Mycologia 1999; 91: 219-227.

[16] Shepherd KL Functions for fish mucus. Rev Fish Biol Fisher 1994; 4: 401-29.

[17] Poll CP. Wound management in amphibians: etiology and treatment of cutaneous lesions. J Exot Pet Med2009; 18: 20-35.

[18] Enoch S, Grey JE, Harding KG. ABC's of wound healing: recent advances and emerging treatments. BMJ 2006; 332: 962-965.

[19] Frayn KN. Hormonal Control of Metabolism in Trauma and Sepsis. Clinical Endocrinology 1986; 24: 577-599.

[20] O’Mahoney JB, Palder SB, Wood JJ, McIrvine A, Rodrick ML, Demling RH, Mannick JA. Depression of cellular immunity after multiple trauma in the absence of sepsis. J Trauma 1984; 24: 86975.

[21] McCarter MD, Mack VE, Daly JM, Naama HA, Calvano SE. Trauma-induced alterations in macrophage function. Surgery 1998; 123: $96-101$

[22] Robinson J, Griffiths RA, Jeffries P. Susceptibility of frog (Rana temporaria) and toad (Bufo bufo) eggs to invasion by Saprolegnia. Amphib-Reptilia 2003; 24: 261-8.

[23] Villa, J. Two fungi lethal to frog eggs in Central America. Copeia 1979; 1979: 650-655.

[24] Bruno DW, Wood BP. Saprolegnia and other Oomycetes. In: Woo PTK, Bruno DW. Eds. Fish Diseases and Disorders, Viral, Bacterial and Fungal Infections, vol. 3. Oxon, United Kingdom: CABI Publishing, Wallingford. 1999; pp. 599-659.

[25] Densmore, CL, Green DE. Diseases of amphibians. ILAR J 2007; 48: 235-54.

[26] Breden F. The effect of post-metamorphis dispersal on the population genetic structure of Fowler's Toad, Bufo woodhousei fowleri. Copeia 1987; 1987: 386-95.
[27] Longcore JE, Pessier AP, Nichols DK. Batrachochytrium dendrobatidis gen. et sp. nov., a chytrid pathogenis to amphibians. Mycologia 1999; 91: 219-227.

[28] Hyatt AD, Boyle DG, Olsen V, Boyle DB, Berger L, Obendorf A, Kriger K, Hero M, Hines H, Phillot R, Cambell R, Marantelli G, Gleason F, Colling A. Diagnostic assays and sampling protocols for the detection of Batrachochytrium dendrobatidis. Dis Aquat Organ 2007; 73: 175-192.

[29] Woodhams DC, Rollins-Smith LA, Alford RA, Simon MA, Harris RN Innate immune defenses of amphibian skin: antimicrobial peptides and more. Anim Conserv 2007; 10: 425-428.

[30] Pessier AP, Nichols DK, Longcore JE, Fuller MS. Cutaneous chytridiomycosis in posion dart frogs (Dendrobates spp. and White's tree frogs (Litorea caerulea). J Vet Diagn Invest 1999; 11: 194199.

[31] Flajnick MF, Pasquier LD. Evolution of the immune system In: Paul WH. Ed. Fundamental Immunology. Philadelphia, PA: Lippincott Williams \& Wilkins 2008; pp. 56-124.

[32] Richmond JQ, Savage AE, Zamudio KR, Rosenblum EB. Toward immunogenic studies of amphibian chytridiomycosis: linking innate and acquired immunity. Bioscience 2009; 59: 311-20.

[33] Elkan E, Cooper JE. Skin biology of reptiles and amphibians. Proc Roy Soc Edin B 1980; 79: 115-126.

[34] Paetow LJ, McLaughlin JD, Cue RI, Pauli BD, Marcogliese DJ. Effects of herbicides and the chytrid fungus Batrachochytrium dendrobatidis on the health of post-metamorphic northern leopard frogs (Lithobates pipiens). Ecotoxicol Environ Saf 2012; 80: 372 80 .

[35] Padgett-Flohr GE. Pathogenicity of Bartachochytrium dendrobatidis in two threatened California amphibians: Rana draytonii and Ambystoma californiense. Herpetol Conserv Biol 2008; 3: 182191.

[36] Berger L. Speare R, Skerratt LF. Distribution of Batrachochytrium dendrobatidis and pathology in the skin of green tree frogs Litoria caerulea with sever chytridiomycosis. Dis Aquat Organ 2005; 68: 65-70.

[37] Benson BJ, Hadley ME. In vitro characterization of adrenergic receptors controlling skin gland secretion in two anurans Rana pipiens and Xenopus laevis. Comp Biochem Physiol 1969; 30: 857-864.

[38] Holmes C, Balls M. In vitro studies on the control of myoepithelial cell contractions in the granular glands of Xenopus laevis skin. Gen Comp Endocrinol 1978; 36: 255-263.

[39] Bly JE, Lawson LA, Szalai AJ, Clem LW. Environmental factors affecting outbreaks of winter saprolegniosis in channel catfish, Ictalurus punctatus (Rafinesque). J Fish Dis 1993; 16: 541-549. 